\title{
Establishment and validation of a nomogram and web calculator for the risk of new vertebral compression fractures and cement leakage after percutaneous vertebroplasty in patients with osteoporotic vertebral compression fractures
}

\author{
Wenle $\mathrm{Li}^{1,2} \cdot$ Haosheng Wang ${ }^{3} \cdot$ Shengtao Dong ${ }^{4} \cdot$ Zhi-Ri Tang $^{5} \cdot$ Longhao Chen $^{6} \cdot$ Xintian Cai $^{7} \cdot$ Zhaohui Hu$^{8}$. \\ Chengliang Yin ${ }^{9,10,11}$
}

Received: 20 March 2021 / Revised: 7 November 2021 / Accepted: 10 November 2021 / Published online: 25 November 2021

(c) The Author(s) 2021

\begin{abstract}
Purpose The aim of this work was to investigate the risk factors for cement leakage and new-onset OVCF after Percutaneous vertebroplasty (PVP) and to develop and validate a clinical prediction model (Nomogram).

Methods Patients with Osteoporotic VCF (OVCF) treated with PVP at Liuzhou People's Hospital from June 2016 to June 2018 were reviewed and met the inclusion criteria. Relevant data affecting bone cement leakage and new onset of OVCF were collected. Predictors were screened using univariate and multi-factor logistic analysis to construct Nomogram and web calculators. The consistency of the prediction models was assessed using calibration plots, and their predictive power was assessed by tenfold cross-validation. Clinical value was assessed using Decision curve analysis (DCA) and clinical impact plots.

Results Higher BMI was associated with lower bone mineral density (BMD). Higher BMI, lower BMD, multiple vertebral fractures, no previous anti-osteoporosis treatment, and steroid use were independent risk factors for new vertebral fractures. Cement injection volume, time to surgery, and multiple vertebral fractures were risk factors for cement leakage after PVP. The development and validation of the Nomogram also demonstrated the predictive ability and clinical value of the model. Conclusions The established Nomogram and web calculator (https://dr-lee.shinyapps.io/RefractureApp/) (https://dr-lee. shinyapps.io/LeakageApp/) can effectively predict the occurrence of cement leakage and new OVCF after PVP.
\end{abstract}

Keywords Osteoporotic compression fractures · Percutaneous vertebroplasty $\cdot$ Bone cement leakage $\cdot$ Risk factors · Nomogram $\cdot$ Web calculator

\section{Introduction}

With the aging of the population and the increase of average life expectancy, osteoporosis shows an increasing trend. Osteoporotic vertebral compression fractures (OVCF) are among the main complications, where there are about 1.4

Wenle Li, Haosheng Wang and Shengtao Dong contributed equally to this work.

Zhaohui $\mathrm{Hu}$

329870376@qq.com

Chengliang Yin chengliangyin@163.com

Extended author information available on the last page of the article million new OVCF around the world every year [1, 2]. OVCF is a common disease for elderly patients. Usually, OVCF causes long-term back pain in older adults and affects their mobility and daily activities, reducing their quality of life and bringing heavy financial burdens on their family [3, 4]. Percutaneous vertebroplasty (PVP) has been widely used in clinical practice due to its advantages in relieving pain and partially restoring vertebral height $[5,6]$. However, as with other invasive procedures, there are risks associated with PVP, the most common of which are leakage of bone cement and new OVCF [7].

New OVCF is common in osteoporosis patients receiving PVP [8]. When occurring new OVCF, it may require reoperation or conservative treatment, both of which will seriously affect the quality of patient's life [9]. According to 
related studies, the incidence of new OVCF (both adjacent and non-adjacent) is $5.5-52.0 \%$. $17.4 \%$ of patients with VCF have a new fracture within a year, which may be related to osteoporosis's natural course [10]. Some studies have pointed out that more than two OVCF are risk factors for developing new OVCF after PVP [11]. Bone cement leakage may cause higher incidence of new OVCF. Some other potential risk factors also did, including age, sex, Bone mineral density (BMD), Body mass index (BMI), and cement injection volume $[4,12,13]$.

Bone cement leakage is the most common complication associated with PVP, whose incidence ranges from 5 to $80 \%$ [14-16]. At the same time, bone cement leakage may present a risk factor for new OVCF after PVP [4, 17, 18], and the pain caused by the leak will seriously reduce the quality of patient's life [19, 20]. Currently, risk factors about bone cement leakage are not completely confirmed and still controversial, including age, sex, Bone mineral density (BMD), Body mass index (BMI), injection volume of bone cement, steroid use, and some underlying chronic diseases [21, 22]. Considering that the existence of underlying diseases may lead to longer preoperative preparation, length of hospital stay and surgery duration, some other factors such as time from injury to surgery, time from hospitalization to surgery, and surgery duration are also included as predictors.

Nomogram is used worldwide to calculate the possibility of generating clinical events through complex computational formulas [23]. With the help of Nomogram, clinicians can assess the risk of clinical events, develop individualized treatment plans and follow-up more aggressively [24]. Considering the additional burden that post PVP bone cement leakage and new OVCF places on patients, this study evaluates OVCF patients treated with PVP using the Nomogram for identifying patients at high risk of bone cement leakage and new OVCF. To facilitate clinicians and others, a webbased calculator was created to facilitate use in assessing risk.

\section{Materials and methods}

\section{Clinical data and selection criteria}

Patients with OVCFS who underwent PVP surgery in Liuzhou People's Hospital from June 2016 to June 2018 were retrospectively analyzed. All patients were followed up for two years. The Institutional Review Board of Liuzhou People's Hospital has approved the plan. All patients had undergone PVP procedure interpretation and clinical data processing. Furthermore, written informed consents were received from all patients.

Bone mineral density (BMD) of L2 L4 vertebral bodies was measured. Bone mineral density was measured by dual-energy X-ray absorptiometry (Osteocore 3, Medilink, Mauguio, France), and corresponding $t$-scores were calculated. The height and weight of each patient were also recorded to calculate BMI.

Inclusion criteria include primary osteoporosis whose bone density met the World Health Organization diagnostic criteria for osteoporosis, pain or local tenderness consistent with imaging findings, preoperative spinal X-ray and Magnetic resonance imaging (MRI) results, initial treatment with PVP, and new fractures detected by MRI after PVP. Exclusion criteria were non-osteoporotic VCF or compression fracture stress secondary to other factors, such as pathological fractures caused by metastatic tumors or hemangiomas, no PVP treatment, preoperative nerve root symptoms or spinal cord compression symptoms and clear history of trauma or no MRI examination for the new fracture after PVP.

\section{Percutaneous vertebroplasty (PVP)}

In this study, all PVP operations adopted the unilateral lateral approach to the vertebral arch. The amount of bone cement injection was determined by the size of the vertebral body and the degree of compression and leakage of the vertebral body. The $\mathrm{C}$-arm X-ray machine was adjusted preoperatively. The patient's vertebral body's lower endplate was presented as a one-line shadow through the anteroposterior film. Bilateral pedicles were equidistant from the spinous process. Laterally, the endplate and the upper and lower edges of the pedicle were in line. Vital signs were monitored intraoperatively, and patients were in the prone position with regular skin disinfection. The puncture point was $3-4 \mathrm{~cm}$ near the spine with $5-10 \mathrm{ml}$ $1 \%$ lidocaine anesthesia infiltrates until the periosteum. The cement needle puncture point was $3-4 \mathrm{~cm}$ near the spine with $30-45^{\circ}$ abducent angles. Needle to the anterior $1 / 3$ and adjust according to the location and depth of the needle. The puncture needlepoint should be in the vertebral body up and down the upper one-third of level and computer direction first $1 / 3$. Pull out the pillow core observation after the presence of active bleeding. The bone cement powder ratio is $1: 1$, which was pumped into $10 \mathrm{ml}$ syringes, gently pushed the pressor to the bone cement to the syringe mouth, and gradually injected under pressure when the bone cement filaments. A fluoroscope was used to monitor whether the bone cement was leaking or exceeding the midline of the vertebral body. The movement of the patient's lower limbs was also monitored. After 2-5 min, the pressurizer and syringe were removed and inserted into the needle core. After $2 \mathrm{~min}$, the needle was pulled out, and the sterile dressing was applied under pressure for $3 \mathrm{~min}$. The operation was over. 


\section{New OVCF identification criteria}

The recurrence of patients with chest and lumbago was related to obvious tenderness in the corresponding site. $\mathrm{X}$-ray examination showed corresponding partial wedge changes in OVCF, and MRI examination confirmed the presence of a new fracture. MRI showed low signal intensity on T1-weighted images and high signal intensity on T2-weighted images. MRI was also used to rule out other spinal diseases, including infections and malignancies.

\section{Postoperative bone cement leakage}

X-rays or CT scans were performed on all patients within three days after PVP surgery to assess the presence of cement leakage.

\section{Statistical analysis}

\section{Risk factors}

Univariate and multivariate analyses were performed on the occurrence of bone cement leakage and new OVCF after PVP to identify the related factors and risk factors. In univariate analysis, the $\mathrm{t}$-test was performed on the samples to analyze quantitative data, and the chi-square test was used to analyze qualitative data. Logistic regression was used to analyze the occurrence relationship among bone cement leakage and age, sex, BMI, BMD, injection volume, injury to surgery, hospitalization to surgery, surgery time, and multiple vertebral fractures and steroid use. Besides, the possible relationship among the occurrence of new OVCF and age, gender, BMI, BMD, bone cement dosage, bone cement leakage, time from injury to surgery, time from admission to surgery, duration of surgery, multiple vertebral fractures, and steroid use were also analyzed. Univariate logistics regression analysis was used to determine its risk factors, and multivariate logistics regression analysis was further used to determine its independent risk factors.

\section{Construction, validation and clinical application of nomogram}

The Nomogram and web calculator were built as predictive models based on the results of logistic regression analysis and previous literature reports. Calibration plots of the clinical prediction models were plotted to determine the consistency of the models. The predictive power of the Nomogram was tested using tenfold cross-validation. The larger the area under the ROC curve (AUC), the stronger the predictive power of the model. The group with the largest AUC value was selected to plot the ROC curve. Decision curve analysis
(DCA), where the Net benefit (NB) was plotted within a reasonable risk threshold consistent with clinical reality, could also be used to assess the clinical utility of the Nomogram for PVP risk and benefit. Based on DCA, clinical impact curve plots were developed to visually estimate the number of patients at risk for each risk threshold.

\section{Statistical methods and software}

Continuous variables were expressed as mean \pm standard deviation (SD), while categorical variables were ratios. Continuous and categorical variables were compared by independent sample $t$-test and chi-square test. IBM SPSS Statistics version 26.0 (SPSS Inc, Chicago, IL, USA) and $\mathrm{R}$ Software version 3.6.2 performed the above statistical methods and applied multiple $\mathrm{R}$ packages, including regplot, RMS, RMDA, and Proc, to plot graphs such as Nomogram, Calibration Plot, DCA plots, and ROC curves. $P<0.05$ was considered statistically significant.

\section{Results}

\section{Patient baseline characteristics}

A total of 385 patients met the inclusion criteria. There were 58 patients with new OVCF after surgery and 327 patients without OVCF. There were 81 patients with bone cement leakage after surgery and 304 patients without it. Chi-square test and independent-sample T-test were conducted, where detailed results were shown in Tables 1 and 2.

\section{Baseline characteristics of the refracture group}

The mean age of patients in the non-newly diagnosed OVCF group was 73.9, and that in the newly diagnosed OVCF group was 75.41 years. There was no statistical difference between the two groups $(P=0.254)$. In the non-newly developed OVCF group, the number of male patients (68 cases, $20.8 \%$ ) was much lower than that of female patients (259 cases, $79.2 \%$ ). The number of male patients ( 9 cases, $15.5 \%$ ) in the newly developed OVCF group was also much lower than that of female patients ( 49 cases, $84.5 \%$ ), which also showed no statistical difference between the two groups. Furthermore, there was no significant differences in height, injection volume, leakage, injury to surgery, hospitalization to surgery, and operation time between the two groups $(P<0.05)$. There was significant differences in body weight between the two groups $(P<0.01)$. The mean weight of the non-newly diagnosed OVCF group was significantly lower than that of the newly diagnosed OVCF group. The BMI was also significantly different $(P<0.01)$. In the newly developed OVCF group, the degree of osteoporosis (lower BMD 
Table 1 Baseline characteristics of patients with no refracture and refracture

\begin{tabular}{|c|c|c|c|}
\hline Variable & $\begin{array}{l}\text { No refrac- } \\
\text { ture group } \\
(N=327)\end{array}$ & $\begin{array}{l}\text { Refrac- } \\
\text { ture group } \\
(N=58)\end{array}$ & $P$ value \\
\hline Age (years) & $73.9 \pm 9.6$ & $75.4 \pm 6.9$ & 0.254 \\
\hline Sex & & & 0.356 \\
\hline Male & $68(20.8 \%)$ & $9(15.5 \%)$ & \\
\hline Female & $259(79.2 \%)$ & $49(84.5 \%)$ & \\
\hline $\operatorname{High}(\mathrm{cm})$ & $154.6 \pm 8.3$ & $154.9 \pm 8.2$ & 0.809 \\
\hline Weigh $(\mathrm{kg})$ & $49.6 \pm 13.3$ & $54.8 \pm 10.7$ & $<0.01$ \\
\hline BMI & $20.7 \pm 5.3$ & $22.8 \pm 3.8$ & $<0.01$ \\
\hline BMD & $-4.3 \pm 0.8$ & $-4.6 \pm 0.6$ & $<0.01$ \\
\hline Hospitalized date (days) & $9.3 \pm 4.7$ & $10.1 \pm 4.3$ & 0.218 \\
\hline Injection volume (ml) & $4.1 \pm 1.0$ & $4.14 \pm 1.2$ & 0.862 \\
\hline Leakage & & & 0.531 \\
\hline No & $260(79.5 \%)$ & $44(75.9 \%)$ & \\
\hline Yes & $67(20.5 \%)$ & $14(24.1)$ & \\
\hline Surgery time (min) & $53.2 \pm 20.3$ & $57.1 \pm 19.6$ & 0.188 \\
\hline $\begin{array}{l}\text { Hospitalization to surgery } \\
\text { (days) }\end{array}$ & $5.2 \pm 2.9$ & $6.1 \pm 3.6$ & 0.053 \\
\hline Injury to surgery (days) & $29.4 \pm 45.3$ & $26.5 \pm 27.0$ & 0.634 \\
\hline Anti-osteoporosis therapy & & & $<0.01$ \\
\hline No & $199(60.9)$ & $46(79.3 \%)$ & \\
\hline Yes & $128(39.1)$ & $12(20.7 \%)$ & \\
\hline Multiple vertebral fracture & & & $<0.01$ \\
\hline No & $185(56.6 \%)$ & $20(34.5 \%)$ & \\
\hline Yes & $142(43.4 \%)$ & $38(65.5 \%)$ & \\
\hline Steroid use & & & $<0.01$ \\
\hline No & $281(85.9 \%)$ & $39(67.2 \%)$ & \\
\hline Yes & $46(14.1 \%)$ & $19(32.8 \%)$ & \\
\hline
\end{tabular}

value) was higher, the proportion of standard anti-osteoporosis therapy was lower, and multiple vertebral fractures and Steroid use were higher in the initial OVCF group $(P<0.01)$. The detailed results were shown in Table 1.

\section{Baseline characteristics of the bone cement leakage group}

There was no significant differences in age, sex, height, weight, BMI, BMD, time from admission to surgery, time from injury to surgery, and steroid use between the two groups $(P<0.05)$. The injection amount of bone cement was significantly different between the two groups $(P<0.05)$. The injection amount of bone cement in the no-leakage group was lower than that in the leakage group. Duration of surgery also varied significantly $(P<0.01)$, where the leakage group's operation time was longer. Additionally, multiple vertebral fractures were more common in the leakage group $(P<0.001)$. The detailed results were shown in Table 2.

\section{Risk factors for new OVCF after surgery}

Logistic regression analysis results were shown in Table 3. Analysis results of univariate Logistic analysis showed that BMI, BMD, postoperative use of anti-osteoporosis therapy, primary OVCF multi-vertebral fracture, and steroid use were related to the risk factors of postoperative new OVCF (all $P<0.05$ ). The $\mathrm{OR}$ value (odds ratio) showed the relative risk of newly developed OVCF.

In multivariate Logistic regression analysis, higher BMI $(\mathrm{OR}=1.094,95 \% \mathrm{CI}=1.035-1.156, P<0.01)$ and more severe osteoporosis $(\mathrm{OR}=1.894,95 \%$ $\mathrm{CI}=1.181-3.038, P<0.01)$ patients were with higher risk. Primary multi-vertebral fracture of OVCF $(\mathrm{OR}=1.929,95 \%$ $\mathrm{CI}=1.028-3.620, P<0.05)$ and steroid use $(\mathrm{OR}=4.070$, $95 \% \mathrm{CI}=2.005-8.264, P<0.05)$ patients were with higher risk. In addition, patients with postoperative standard use of anti-osteoporosis were with lower risk (OR $=0.385,95 \%$ $\mathrm{CI}=0.187-0.792, P<0.05)$. Therefore, high BMI, low BMD, primary multi-vertebral fracture of OVCF and steroid use were independent risk factors for newly diagnosed OVCF after surgery. Furthermore, after surgery, standardized use of anti-osteoporosis after surgery was an independent factor for reducing newly diagnosed OVCF.

\section{Risk factors for postoperative bone cement leakage}

Logistic regression analysis results were shown in Table 4. The univariate logistic analysis results showed that the injection amount of bone cement, the duration of operation, and whether the multiple vertebral fractures were related to the risk factors of bone cement (all $P<0.05$ ). The OR value (odds ratio) showed the relative risk of cement leakage.

In multivariate logistic regression analysis, higher injection volume of bone cement ( $\mathrm{OR}=1.283,95 \%$ $\mathrm{CI}=1.004-1.640, P<0.05)$, longer operation time $(\mathrm{OR}=1.0 .15,95 \% \mathrm{CI}=1.003-1.027, P<0.05)$ and multiple vertebral fractures $(\mathrm{OR}=2.456,95 \% \mathrm{CI}=1.461-4.130$, $P<0.05)$ patients were at greater risk. Therefore, higher injection volume of bone cement, longer operation time, and multiple vertebral fractures were independent risk factors for postoperative bone cement leakage.

\section{Development and validation of the nomogram for the risk of new OVCF after PVP}

Based on the results of the logistic regression analysis in Table $3(p<0.2)$ combined with previous literature, a Nomogram (Fig. 1) and web calculator (https://dr-lee.shinyapps.io/ RefractureApp/) were developed to predict the new OVCF postoperatively. Calibration curves were used to evaluate the predicted results and observed results, showing good agreement (Fig. 2A). The predictive ability of the Nomogram was 
Table 2 Baseline characteristics of patients in the non-leakage group and the leakage group

\begin{tabular}{|c|c|c|c|}
\hline Variable & $\begin{array}{l}\text { Non-leakage group } \\
(N=304)\end{array}$ & Leakage group $(N=81$ & $P$ value \\
\hline Age (years) & $74.3 \pm 8.7$ & $74.3 \pm 8.6$ & 0.885 \\
\hline Sex & & & 0.493 \\
\hline Male & $63(20.7 \%)$ & $14(17.3 \%)$ & \\
\hline Female & $241(79.3 \%)$ & $67(82.7 \%)$ & \\
\hline $\operatorname{High}(\mathrm{cm})$ & $154.3 \pm 8.5$ & $155.7 \pm 14.3$ & 0.187 \\
\hline Weigh (kg) & $50.32 \pm 12.77$ & $50.86 \pm 10.7$ & 0.741 \\
\hline BMI & $21.1 \pm 5.2$ & $20.9 \pm 5.5$ & 0.758 \\
\hline BMD & $-4.38 \pm 0.8$ & $-4.54 \pm 0.5$ & 0.180 \\
\hline Hospitalized date (days) & $9.3 \pm 4.7$ & $9.8 \pm 4.4$ & 0.392 \\
\hline Injection volume $(\mathrm{ml})$ & $4.1 \pm 1.0$ & $4.4 \pm 1.2$ & $<0.05$ \\
\hline Surgery time (min) & $52.3 \pm 18.7$ & $59.5 \pm 24.5$ & $<0.01$ \\
\hline Hospitalization to surgery (days) & $5.28 \pm 2.9$ & $5.86 \pm 3.3$ & 0.128 \\
\hline Injury to surgery (days) & $29.4 \pm 46.0$ & $27.44 \pm 27.8$ & 0.712 \\
\hline Multiple vertebral fracture & & & $<0.001$ \\
\hline No & $177(58.2 \%)$ & $28(34.6 \%)$ & \\
\hline Yes & $127(41.8 \%)$ & $53(65.4 \%)$ & \\
\hline Steroid use & & & 0.119 \\
\hline No & $248(81.6 \%)$ & $72(88.9 \%)$ & \\
\hline Yes & $56(18.4 \%)$ & $9(11.1 \%)$ & \\
\hline
\end{tabular}

Table 3 Univariate and multivariate Logistic regression analysis of recurrent vertebral compression fractures after percutaneous Vertebroplasty in patients with osteoporosis

\begin{tabular}{|c|c|c|c|c|}
\hline Variable & $\begin{array}{l}\text { Univariate } \\
\text { OR }(95 \% \mathrm{CI})\end{array}$ & $P$ value & $\begin{array}{l}\text { Multivariate } \\
\text { OR (95\% CI) }\end{array}$ & $P$ value \\
\hline Age (years) & $1.019(0.987-1.053)$ & 0.252 & - & - \\
\hline \multicolumn{5}{|l|}{ Sex } \\
\hline Male & Ref & Ref & - & - \\
\hline Female & $1.429(0.669-3.054)$ & 0.356 & - & - \\
\hline BMI & $1.070(1.019-1.123)$ & $<0.01$ & $1.094(1.035-1.156)$ & $<0.01$ \\
\hline BMD & $1.914(1.238-2.960)$ & $<0.01$ & $1.894(1.181-3.038)$ & $<0.01$ \\
\hline Hospitalized date (days) & $1.033(0.981-1.088)$ & 0.223 & - & - \\
\hline Injection volume $(\mathrm{ml})$ & $0.976(0.747-1.276)$ & 0.976 & - & - \\
\hline \multicolumn{5}{|l|}{ Leakage } \\
\hline No & Ref & Ref & - & - \\
\hline Yes & $1.235(0.639-2.386)$ & 0.530 & - & - \\
\hline Surgery time (min) & $1.009(0.996-1.022)$ & 0.188 & $1.894(1.181-3.038)$ & 0.181 \\
\hline Hospitalization to surgery (days) & $1.081(0.998-1.171)$ & 0.057 & $1.071(0.981-1.169)$ & 0.124 \\
\hline Injury to surgery (days) & $0.998(0.991-1.006)$ & 0.634 & - & - \\
\hline \multicolumn{5}{|l|}{ Anti-osteoporosis therapy } \\
\hline No & Ref & Ref & Ref & Ref \\
\hline Yes & $0.406(0.207-0.795)$ & $<0.01$ & $0.385(0.187-0.792)$ & $<0.05$ \\
\hline \multicolumn{5}{|l|}{ Multiple vertebral fracture } \\
\hline No & Ref & Ref & Ref & Ref \\
\hline Yes & $2.475(1.38-4.43)$ & $<0.01$ & $1.929(1.028-3.620)$ & $<0.05$ \\
\hline \multicolumn{5}{|l|}{ Steroid use } \\
\hline No & Ref & Ref & Ref & Ref \\
\hline Yes & $2.976(1.584-5.592)$ & $<0.05$ & $4.070(2.005-8.264)$ & $<0.001$ \\
\hline
\end{tabular}


Table 4 Univariate and multivariate Logistic regression analysis of the risk of bone cement leakage after percutaneous vertebroplasty in patients with osteoporosis

\begin{tabular}{lllll}
\hline Variable & Univariate & $P$ value & $\begin{array}{l}\text { Multivariate } \\
\text { OR }(95 \% \text { CI })\end{array}$ & P value \\
\hline Age (years) & $1.000(0.972-1.029)$ & 0.996 & - & - \\
Sex & & & & - \\
Male & Ref & Ref & - & - \\
Female & $1251(0.660-2.371)$ & 0.496 & - & - \\
BMI & $0.993(0.946-1.041)$ & 0.758 & - & - \\
BMD & $1.283(0.897-1.833)$ & 0.172 & - & - \\
Hospitalized date (days) & $1.281(1.004-1.634)$ & 0.394 & - & $<0.05$ \\
Injection volume (ml) & $0.976(0.747-1.276)$ & $<0.05$ & $1.283(1.004-1.640)$ & $<0.05$ \\
Surgery time (min) & $1.017(1.005-1.028)$ & $<0.01$ & $1.015(1.003-1.027)$ & - \\
Hospitalization to surgery (days) & $1.059(0.983-1.140)$ & 0.130 & - & - \\
Injury to surgery (days) & $0.999(0.993-1.005)$ & 0.711 & - & Ref \\
Multiple vertebral fracture & & & & $<0.01$ \\
No & Ref & Ref & Ref & - \\
$\quad$ Yes & $2.638(1.582-4.400)$ & $<0.001$ & $2.456(1.461-4.130)$ & \\
Steroid use & & & & - \\
No & Ref & Ref & - & - \\
Yes & $0.554(0.261-1.173)$ & 0.123 & - & \\
\hline
\end{tabular}

Fig. 1 Nomogram for predicting new-onset OVCF after PVP

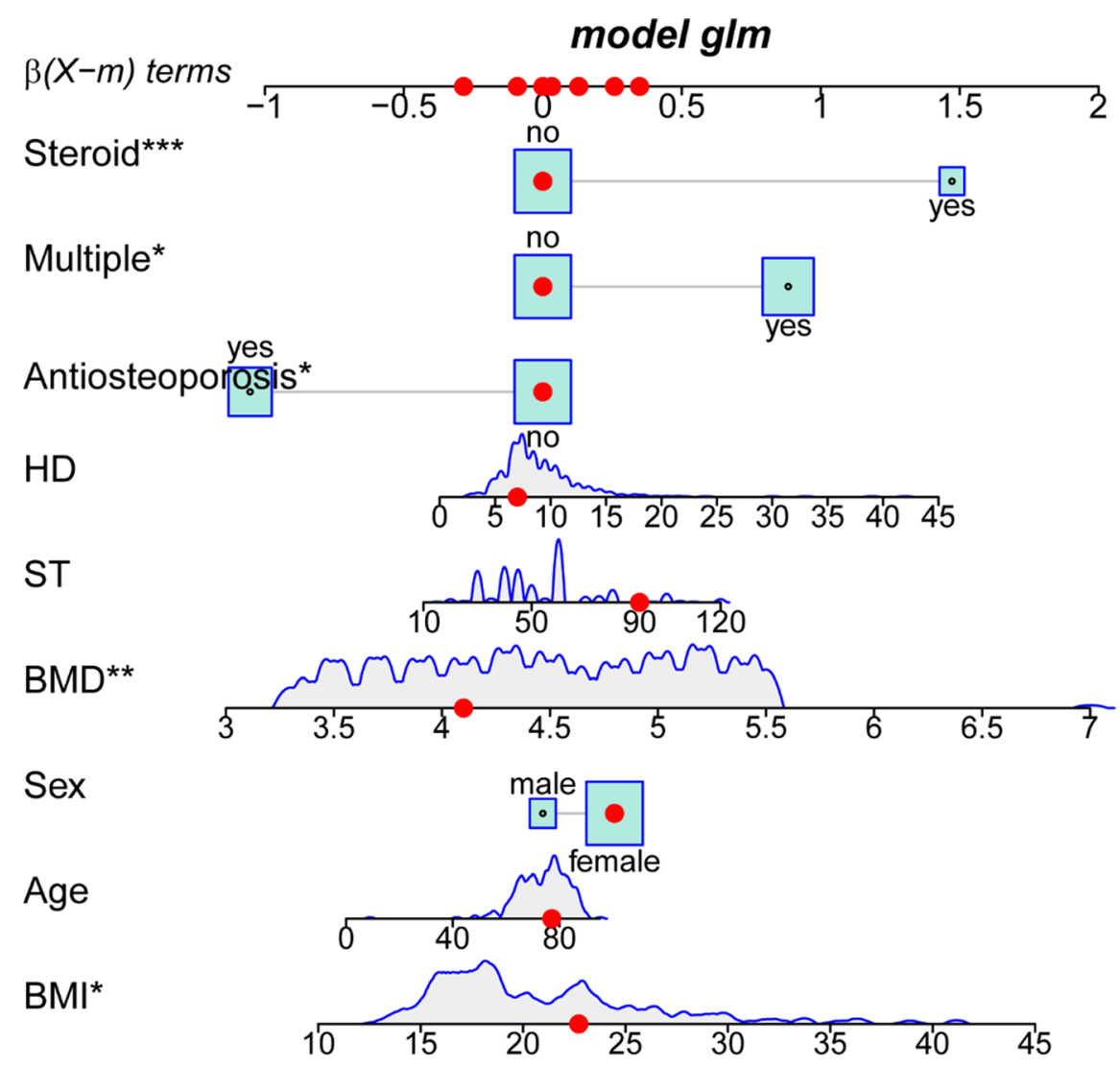

Total score

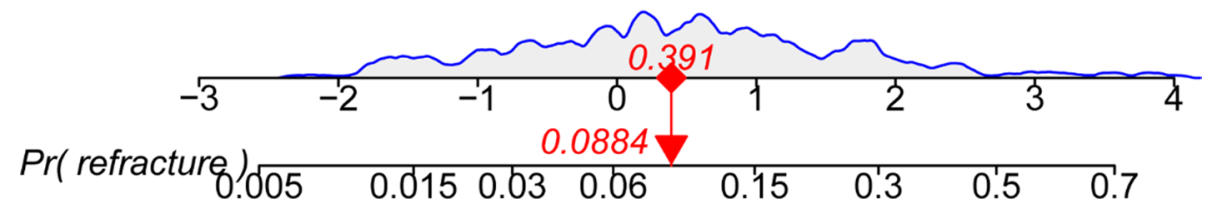


A

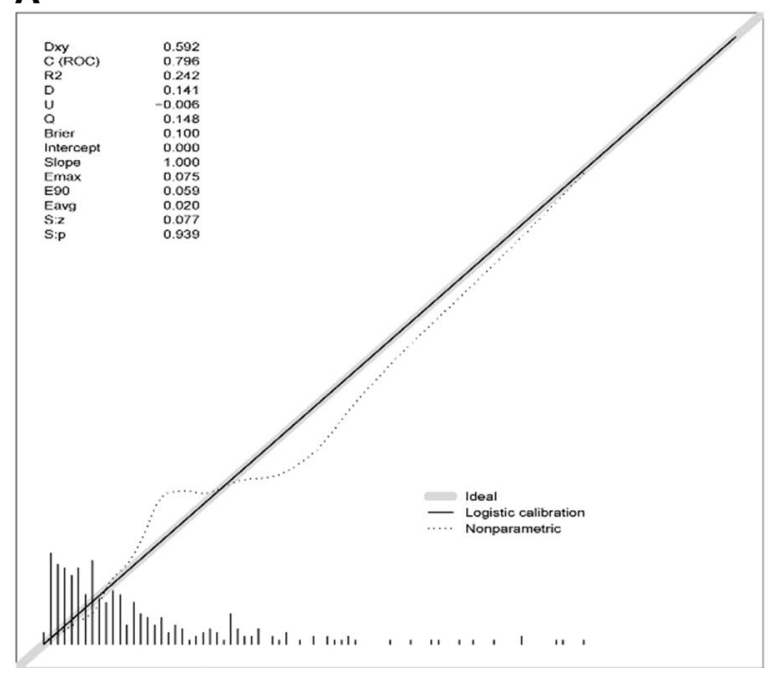

Fig. 2 Calibration plots and ROC curves for predicting new OVCF Nomogram after PVP. A Calibration plot of the Nomogram, showing very good agreement B ROC curve for the highest AUC (0.912) of

validated using tenfold cross-validation with a maximum AUC of 0.912 (Fig. 2B) and a mean AUC of 0.726, indicating that the Nomogram had a good predictive ability.

Figure 1, Nomogram approach: place the values for each patient on each variable axis and draw lines upwards to determine the number of points for each variable value. The sum of these numbers is placed on the total number of points axis. Draw a line down to the probability axis to determine the probability of a new OVCF after surgery. ST: time to surgery; HD: time from admission to surgery.

\section{Development and validation of a nomogram for bone cement leakage risk after PVP}

Based on the results of the logistic regression analysis in Table 4 and previous literature reports, a Nomogram (Fig. 3) and web calculator (https://dr-lee.shinyapps.io/Leaka geApp/) were created for the risk of postoperative bone cement leakage. Calibration plots were used to assess the agreement between the predicted and observed actual results (Fig. 4A). The predictive ability of the Nomogram was validated using tenfold cross-validation with a maximum AUC of 0.793 (Fig. 4B) and a mean AUC of 0.656, indicating that the Nomogram had a good predictive ability.

\section{Clinical utility of nomogram for new OVCF risk after PVP}

As shown in the DCA curve (Fig. 5A), the threshold value of about $0.1-0.8$ had the maximum return. Furthermore, the clinical impact diagram of the training set (Fig. 5B) showed that there were always more expected high-risk patients than

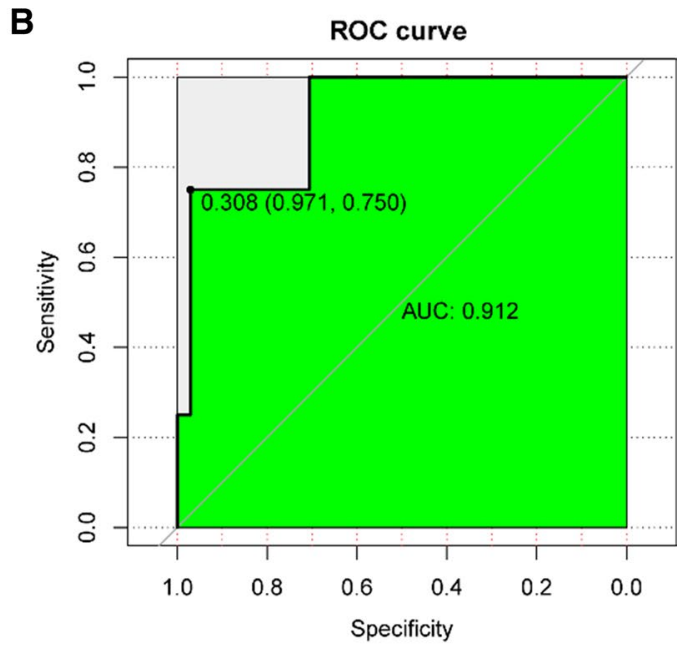

the predicted refraction nomogram after tenfold cross-validation. The mean AUC for tenfold cross-validation was 0.726

actual newly developed OVCF within the most favorable threshold probability range, which was also accompanied by an acceptable cost-benefit ratio.

\section{Clinical applicability of nomogram for bone cement leak during PVP}

As shown in the DCA curve (Fig. 6A), the threshold value of about $0.1-0.7$ had the maximum return. Furthermore, the clinical impact diagram of the training set (Fig. 6b) showed that there were always more expected high-risk patients than actual bone cement patients within the most favorable threshold probability range, which was also accompanied by an acceptable cost-benefit ratio.

\section{Discussion}

The nomogram has now been applied to a variety of conditions, including in the field of spine surgery, such as the nomogram for spine surgery evaluation using patient symptoms, baseline disease, demographics and prior spine care developed by Zach Pennington et al. and the development of prediction calculator about a non-routine discharge and length of stay after spine surgery by Daniel Lubelski et al. $[25,26]$.To the best of our knowledge, our study may be the first to examine the effect of operation duration on postoperative complications of PVP and to use a nomogram to assess the risk of postoperative cement leakage and new compression fractures.

With the aging of the population worldwide, osteoporosis has become a common disease that threatens the health 
Fig. 3 Nomogram of the risk of bone cement leakage after percutaneous Vertebroplasty in patients with osteoporosis

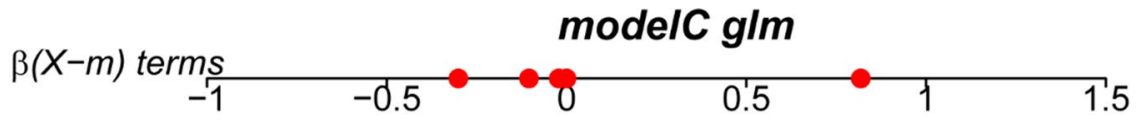

Steroid

Multiple*

IV
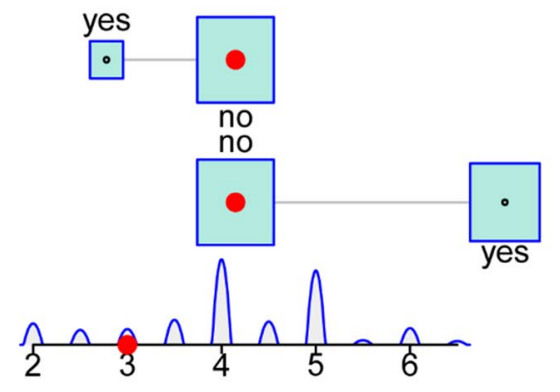

HD

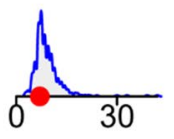

$\mathrm{ST} * *$

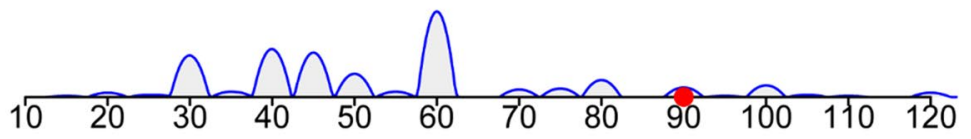

BMD

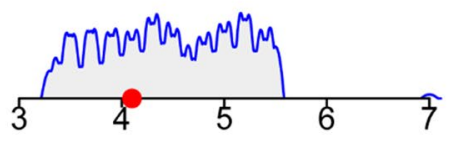

Total score

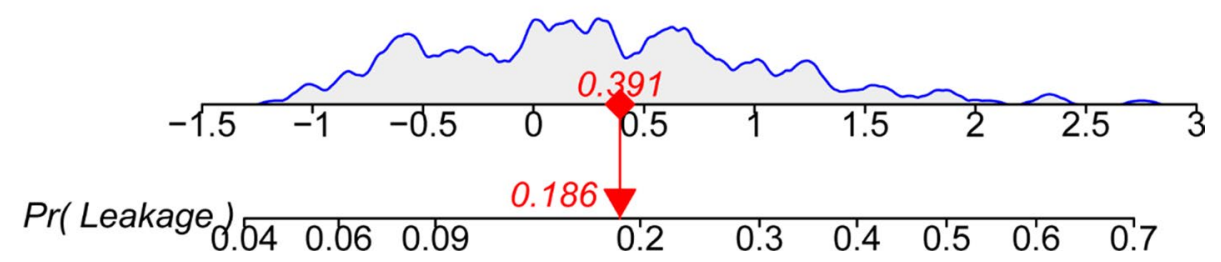

A

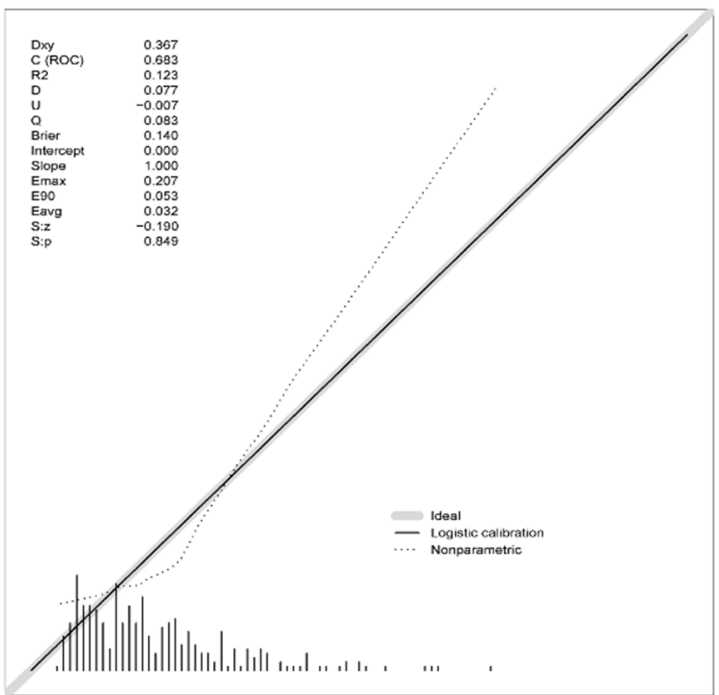

Fig. 4 Calibration plot and ROC curve for predicting bone cement leakage Nomogram A Calibration plot of the predicted bone cement leakage nomogram, showing that it had a good agreement B ROC
B

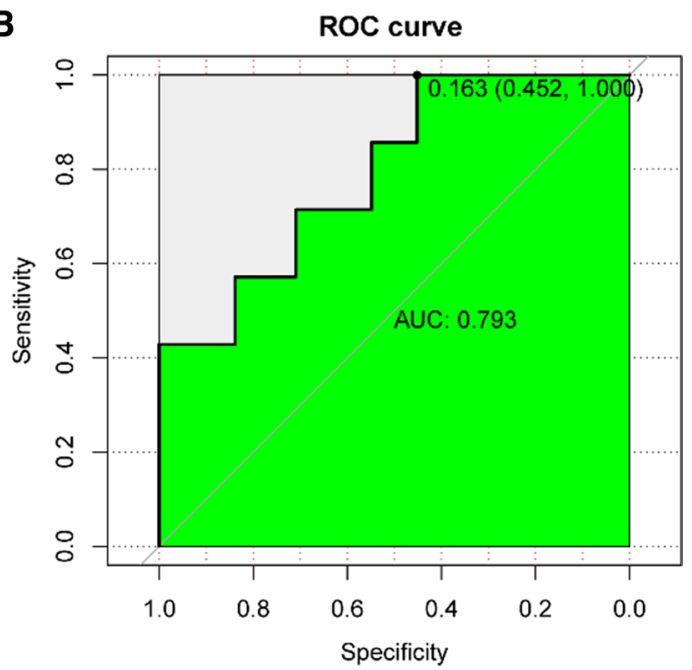

curve of the highest AUC (0.793) of the Nomogram for predicted bone cement leakage after tenfold cross-validation. The mean AUC for tenfold cross-validation was 0.656 


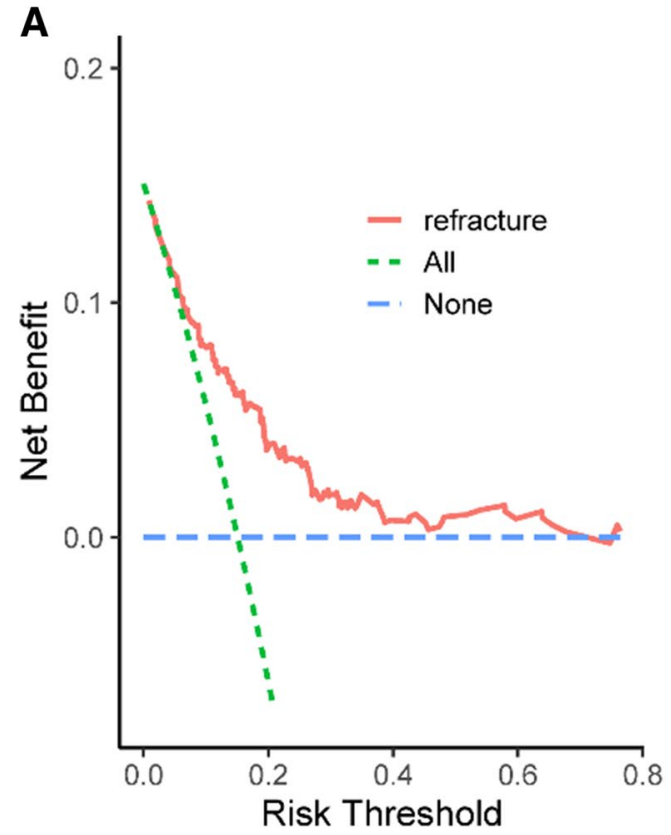

Fig. 5 DCA and clinical impact maps for predicting refacture Nomogram A Nomogram decision curve (DCA) and clinical implications for the risk of new compression fracture after percutaneous osteoplasty. B The red curve (Number of high risks) indicated the num-

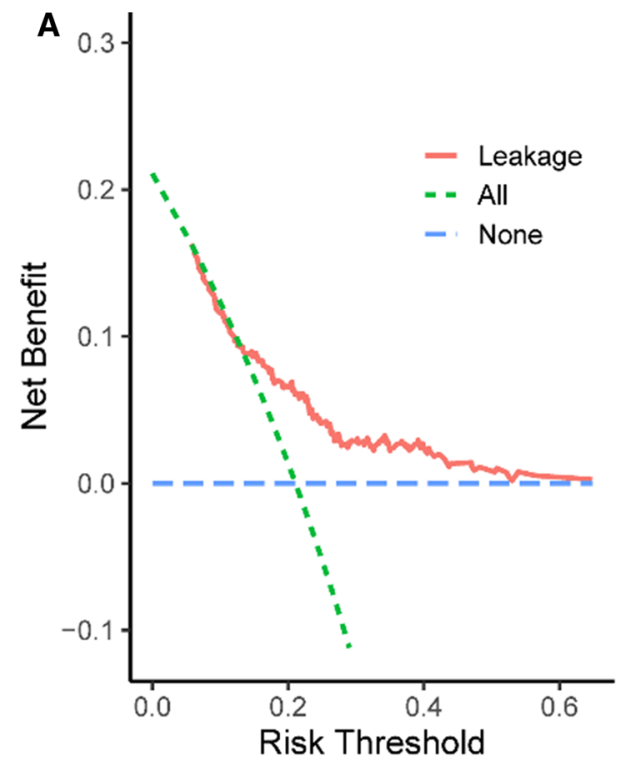

Fig. 6 DCA and clinical impact maps for predicting bone cement leakage. A Nomogram decision curve (DCA) and clinicalimplications for bone cement leakage risk for percutaneousosteoplasty. B The red

of older people, especially postmenopausal women. One of the main complications of this disease is vertebral compression fracture [27]. Considering the high incidence of OVCF and PVP surgery's popularity, it was of great clinical significance to screen out high-risk patients with bone
B

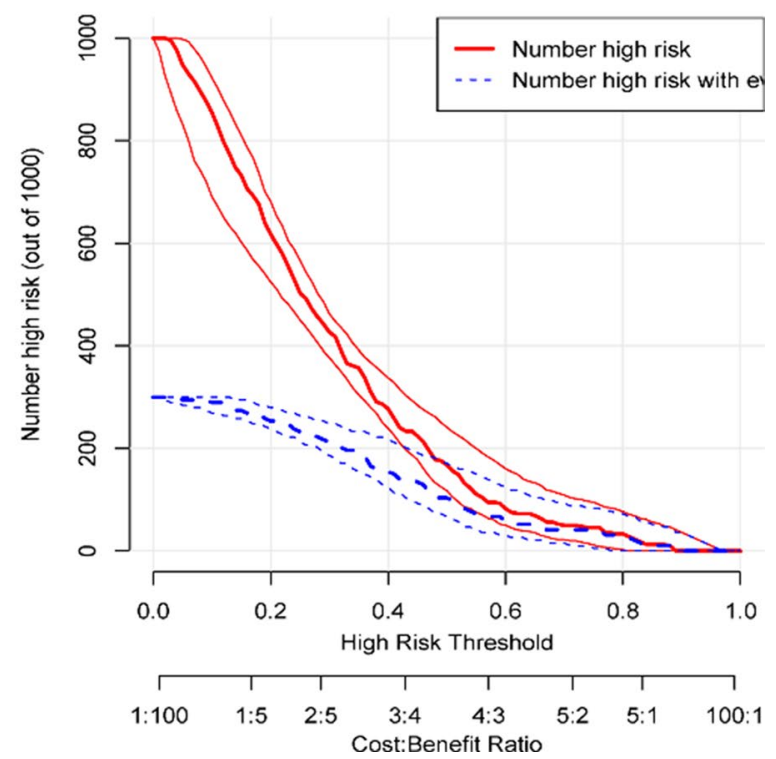

ber of people classified as positive (high risk) by Nomogram for each threshold probability. The blue curve (Number of high risks with the outcome) representd the number of true positives under each threshold probability

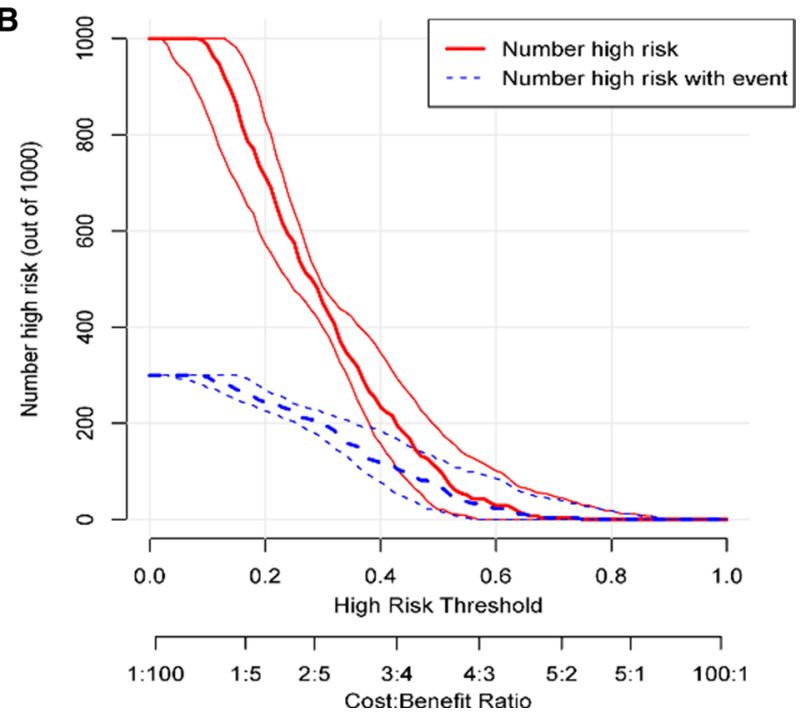

curve indicated the number of peopleclassified as positive by Nomogram for each thresholdprobability. The blue curve represented the number of truepositives under each threshold probability.

cement leakage and newly developed OVCF before PVP. Bone cement leakage was a major complication of PVP, which was asymptomatic in most cases. However, cement leakage in the spinal canal or the foramina may result in nerve compression symptoms. If the symptoms are severe, 
additional decompression surgery may be required [28]. Besides, intervertebral cement leakage may increase the risk of fracture of adjacent vertebrae [29].

The injection volume of bone cement was a concern for the spine surgeon. Studies have demonstrated that the greater the injection amount of bone cement, the higher pain relief caused by OVCF. Therefore, it was recommended to inject more bone cement as much as possible [30]. However, another meta-analysis results suggest that patients who inject large amounts of bone cement may be at a higher risk of bone cement leakage [31]. It was likewise the same as the results of this study. One study recommended the injection of less than $3.5 \mathrm{~mL}$ for the thoracic vertebrae and less than $4.2 \mathrm{~mL}$ for the lumbar vertebrae to avoid cement leakage [32].

The results of this study showed that patients with cement leakage tended to have longer operative time. Longer operation time meant a more difficult operation or more vertebrae need to be operated, which in some ways meant more severe fracture. Simultaneously, the increased severity of the fracture made the operation more difficult, which meant that the surgeon had difficulty getting the needle into the desired location, thus affecting the distribution of the bone cement [32]. Therefore, whether the duration of the operation itself or the influence of other factors (such as fracture severity) led to an increase in the risk of bone cement leakage further needed further study and analysis.

Studies had shown that when the first OVCF was diagnosed, and new multi-vertebral OVCF would repeatedly occur [33]. MS OVCF causes the spine to shorten and bend forward, which can develop into scoliosis or kyphosis, even with severe lower back pain. The kyphosis not only made it difficult to walk and reach objects but also caused chronic back pain and loss of height over time [34]. It has been proved by relevant clinical practice that PVP is an effective method for the treatment of OVCF and is widely used in clinical practice. However, newly developed OVCF is common after surgery. Related studies indicated that the incidence of OVCF is about 6.5-51\% [35], which was one reason that seriously affects the postoperative quality of life of patients with PVP [17, 36, 37]. The cause of the new OVCF was currently controversial. Some scholars believed that the emergence of new OVCF one year after PVP might be a natural process of senile osteoporosis [29]. Whether PVP can lead to an increased risk of new OVCF in adjacent vertebral bodies has not been confirmed yet $[38,39]$. Some scholars believed that PVP was not a risk factor for new OVCF and can prevent further height loss [40]. A metaanalysis concluded that PVP as a minimally invasive procedure for the treatment of OVCF was a better option than conventional treatment because these techniques provided not only immediate relief of back pain but also avoided many complications in patients who became bed-bound due to conservative treatment, and might not increase the incidence of new OVCF in the adjacent vertebral body [41].

In previous studies, women, older age, and low BMD have been identified as significant risk factors for OVCF [42]. Elderly patients and postmenopausal women usually had lower BMD, which might be why new OVCF and low BMD always appeared together after PVP. Logistic regression analysis was performed on gender, age and BMD in this study. There was no statistical difference between gender and age $(P<0.05)$, while BMD had a significant difference $(P<0.01)$. Considering the limited sample size and the single-center retrospective study, there was a risk of bias in the data.

The results of statistical analysis showed that the average body weight and BMI of the newly developed OVCF group were $(54.86 \pm 10.7) \mathrm{kg}$ and $(22.8 .77 \pm 2.16) \mathrm{kg} / \mathrm{m} 2$, which were significantly higher than those of the non-newly developed OVCF group (49.65.40 \pm 13.13$) \mathrm{kg}$ and body mass index $(20.74 \pm 5.38) \mathrm{kg} / \mathrm{m} 2$. Compared to body weight, BMI can reflect the degree of body obesity more objectively and reduce the error caused by different heights. Thus, BMI was included in the Logistic regression correlation analysis. Most OVCF patients were postmenopausal women and older adults who was usually overweight and had a higher than normal BMI [43]. Considering dietary habits, lack of exercise and use of hormonal medications, estrogen levels in postmenopausal women tent to drop sharply, which leads to a gradual decline in BMD, as in older adults [44]. These patients with high BMI had a higher incidence of severe osteoporosis and new-onset OVCF after PVP surgery, which was consistent with this study's results. Similarly, logistics analysis results show that the OR value of standard antiosteopathic therapy was $0.385,95 \%$ CI is $0.187-0.792$, $P<0.05$, where there was a statistically significant difference (Table 2). Therefore, it was suggested that postoperative standard anti-osteoporosis treatment, increasing patient $\mathrm{BMD}$, and lowering BMI can effectively reduce the risk of new OVCF after surgery.

Older patients tent to have more underlying medical conditions, resulting in longer hospital stays, and often had a longer surgical duration due to difficulty in cooperating with doctors during surgery [45]. Considering these factors, this study collected the time from admission to surgery and surgery duration for analysis. Analysis results showed no significant statistical difference $(P>0.05)$. The amount of cement injection and the presence of leakage were also factors of concern. Whether these factors increased the risk of newly diagnosed OVCF, various studies were different in different cases and different regions, which had no straightforward conclusion. In this study, the authors compared the injection volume and leakage of bone cement between the newly diagnosed OVCF group and the non-newly diagnosed OVCF group. There was no statistically significant 
difference between the two groups $(P>0.05)$. Although this finding did not support the hypothesis that excessive cement and leakage increased the risk of adjacent fractures, reliable conclusions could not be drawn due to the small sample size of this study's cases. A further focus was required on this point, and a larger sample size was needed to draw reasonable conclusions.

Multiple vertebral fractures during the first OVCF were regarded as a risk factor for new OVCF after PVP. A clinical study found no difference in the incidence of new OVCF between PVP and conservative treatment. The number of initial OVCF was the only risk factor for new OVCF after surgery [9]. Simultaneously, some studies found that the presence of more than two preexisting OVCF was the only independent risk factor for new OVCF [46]. However, some studies believed that the occurrence of new fractures after PVP was not related to the number of initial OVCF [47]. The results of this study confirmed that multiple initial OVCF segments had a 1.92-fold higher risk of new OVCF than single postoperative ones $(\mathrm{OR}=1.929,95 \% \mathrm{CI}=1.028-3.620$, $P<0.05)$. This may be related to the fact that patients with multiple vertebral compression fractures may have a more severe osteoporosis. Meanwhile, whether the cemented strengthening of multiple vertebrae leads to an increased force in the remaining uncemented vertebrae had no firm conclusion [48]. A meta-analysis and a review concluded that there was no increased risk of compression fractures in the remaining uncemented vertebrae after the cemented strengthening of the vertebrae [49]. Considering the advantages of PVP in terms of vertebral height restoration and avoiding the serious consequences of prolonged bed rest due to pain in the elderly, an analysis of insurance claims data showed that patients treated with PVP had lower mortality and morbidity rates compared to conservative treatment [50].Therefore, taking into account the possible complications of their PVP, such as new-onset OVCF, we still recommend seeking the opportunity to undergo PVP treatment when possible.

This study attempted to use a new Nomogram to predict the likelihood of bone cement leakage and new OVCF in OVCF patients after PVP. This Nomogram approach had been proved to be a reasonable and feasible approach in multiple disease models [51]. The screening of Nomogram predictors has not been confirmed. Standard criteria included statistical analysis $(P<0.2)$, clinical experience, literature reports and other factors [52]. In this study, statistics, relevant literature and clinical experience were integrated. Nomogram was constructed by incorporating predictors with univariate logistics analysis integrated into $P<0.2$ and previous research results. The ROC curves, as well as the AUC values of the two nomograms, demonstrated excellent predictive performance of the two nomograms.
However, ROC has some shortcomings, as it only predicts the model's accuracy and is not a guide to the value of the model in clinical practice. DCA is a method of assessing the benefits of treatment in a range of patients and is used to analyze the risk of under- and over-treatment to facilitate the choice of treatment modality. As could be visually observed in Figs. 5A and 6A, the DCA was represented as a curve with a gain score on the vertical axis and a probability threshold on the horizontal axis. Predicting the risk of new compression fractures after surgery (Fig. 5A) at 0.1 to approximately 0.8 and predicting the risk of cement leakage after PVP (Fig. 6A) at 0.1 to approximately 0.7 both had good gain values. Therefore, clinicians need to look at whether to continue treatment with PVP when the patient's risks outweigh the benefits when performing PVP.

Based on previous studies, clinicians could not calculate the probability of postoperative bone cement leakage and new OVCF based on the identified risk factors. With this Nomogram, clinicians could use an accurate and easily implemented method to calculate the probability of bone cement leakage and new OVCF after PVP, which was of profound significance for postoperative prevention, treatment, and targeted follow-up. It also guides further prospective studies.

This study has some limitations: (1) The clinical data are from the orthopedics department of our hospital, and lack of comparison with various centers; (2) Compared to inpatients, the compliance of out-of-hospital patients decrease to a greater extent, which may lead to the loss of follow-up data to a certain extent. (3) As a retrospective study, there may be a certain degree of selection bias. Therefore, it is necessary to conduct a prospective study to verify the accuracy of this Nomogram.

\section{Conclusions}

This study showed that the independent risk factors for new OVCF after PVP in OVCF patients were BMI, BMD, multiple vertebral fractures in primary OVCF, failure to receive anti-osteoporosis treatment, and steroid use. The independent risk factors for bone cement leakage after PVP in OVCF patients were higher cement injection volume, longer operative time, and multiple vertebral fractures. The creation of a Nomogram and webpage calculator can objectively and accurately predict the probability of new OVCF and the likelihood of postoperative cement leakage and can help clinicians to conveniently assess the risk of clinical events and personalize treatment plans. 
Authors' contributions CLY and ZHH designed the study. WLL, CLY and HSW performed the study and analyzed the data. WLL, HSW and STD wrote the manuscript. ZRT provided the expert consultations and clinical suggestions. LHC, XTC and ZHH conceived of the study, XTC participated in its design and coordination, ZRT helped to draft the manuscript. All authors reviewed the final version of the manuscript.

Funding This study was supported by the Medical Big Data and AI R\&D Project of Chinese PLA General Hospital (2019MBD-001), the National Natural Science Foundation of China (81260274) and the Science and Technology Research and Development Program of Liuzhou City (2014J030405).

Data availability All data in this article can be requested by communicating with the author of the communication.

\section{Declarations}

Conflict of interest The authors declare that they have no competing interests.

Ethics approval This study was approved by the Ethics Committee of Liuzhou People's Hospital. NO.Ethical audit 2020(KY-E-22-01).

Open Access This article is licensed under a Creative Commons Attribution 4.0 International License, which permits use, sharing, adaptation, distribution and reproduction in any medium or format, as long as you give appropriate credit to the original author(s) and the source, provide a link to the Creative Commons licence, and indicate if changes were made. The images or other third party material in this article are included in the article's Creative Commons licence, unless indicated otherwise in a credit line to the material. If material is not included in the article's Creative Commons licence and your intended use is not permitted by statutory regulation or exceeds the permitted use, you will need to obtain permission directly from the copyright holder. To view a copy of this licence, visit http://creativecommons.org/licenses/by/4.0/.

\section{References}

1. Zhang H, Xu C, Zhang T, Gao Z, Zhang T (2017) Does Percutaneous Vertebroplasty or Balloon Kyphoplasty for Osteoporotic Vertebral Compression Fractures Increase the Incidence of New Vertebral Fractures? A Meta-Analysis. Pain Physician 20:E13-e28

2. Johnell O, Kanis JA (2006) An estimate of the worldwide prevalence and disability associated with osteoporotic fractures. Osteoporos Int 17:1726-1733. https://doi.org/10.1007/ s00198-006-0172-4

3. Lavelle W, Carl A, Lavelle ED, Khaleel MA (2007) Vertebroplasty and kyphoplasty. Anesthesiol Clin 25:913-928. https://doi. org/10.1016/j.anclin.2007.07.011

4. Chen Z, Chen Z, Wu Y, Wu Y, Ning S, Ning S, Ma T, Ma T, Wu Z, Wu Z (2019) Risk Factors of Secondary Vertebral Compression Fracture After Percutaneous Vertebroplasty or Kyphoplasty: A Retrospective Study of 650 Patients. Med Sci Monit 25:92559261. https://doi.org/10.12659/msm.915312

5. Yang EZ, Xu JG, Huang GZ, Xiao WZ, Liu XK, Zeng BF, Lian XF (2016) Percutaneous Vertebroplasty Versus Conservative Treatment in Aged Patients With Acute Osteoporotic Vertebral Compression Fractures: A Prospective Randomized Controlled Clinical Study. Spine 41:653-660
6. Klazen CA, Lohle PN, de Vries J, Jansen FH, Tielbeek AV, Blonk MC, Venmans A, van Rooij WJ, Schoemaker MC, Juttmann JR, Lo TH, Verhaar HJ, van der Graaf Y, van Everdingen KJ, Muller AF, Elgersma OE, Halkema DR, Fransen H, Janssens X, Buskens E, Mali WP (2010) Vertebroplasty versus conservative treatment in acute osteoporotic vertebral compression fractures (Vertos II): an open-label randomised trial. Lancet 376:1085-1092. https:// doi.org/10.1016/s0140-6736(10)60954-3

7. Chang W, Zhang X, Jiao N, Yuwen P, Zhu Y, Zhang F, Chen W (2017) Unilateral versus bilateral percutaneous kyphoplasty for osteoporotic vertebral compression fractures: A meta-analysis. Medicine 96:e6738. https://doi.org/10.1097/md.0000000000 006738

8. Voormolen MH, Lohle PN, Juttmann JR, van der Graaf Y, Fransen H, Lampmann LE (2006) The risk of new osteoporotic vertebral compression fractures in the year after percutaneous vertebroplasty. J Vascular Interventional Radiol 17:71-76. https://doi.org/ 10.1097/01.Rvi.0000190910.43602.3c

9. Klazen CA, Venmans A, de Vries J, van Rooij WJ, Jansen FH, Blonk MC, Lohle PN, Juttmann JR, Buskens E, van Everdingen KJ, Muller A, Fransen H, Elgersma OE, Mali WP, Verhaar HJ (2010) Percutaneous vertebroplasty is not a risk factor for new osteoporotic compression fractures: results from VERTOS II. AJNR Am J Neuroradiol 31:1447-1450. https://doi.org/10.3174/ ajnr.A2148

10. Lindsay R, Burge RT, Strauss DM (2005) One year outcomes and costs following a vertebral fracture. Osteoporos Int 16:78-85. https://doi.org/10.1007/s00198-004-1646-x

11. Li H, Yang DL, Ma L, Wang H, Ding WY, Yang SD (2017) Risk Factors Associated with Adjacent Vertebral Compression Fracture Following Percutaneous Vertebroplasty After Menopause: A Retrospective Study. Med Sci Monit 23:5271-5276. https://doi. org/10.12659/msm.907364

12. Tseng YY, Yang TC, Tu PH, Lo YL, Yang ST (2009) Repeated and multiple new vertebral compression fractures after percutaneous transpedicular vertebroplasty. Spine 34:1917-1922

13. Lin WC, Lee YC, Lee CH, Kuo YL, Cheng YF, Lui CC, Cheng TT (2008) Refractures in cemented vertebrae after percutaneous vertebroplasty: a retrospective analysis. Eur Spine J 17:592-599. https://doi.org/10.1007/s00586-007-0564-y

14. Schmidt R, Cakir B, Mattes T, Wegener M, Puhl W, Richter M (2005) Cement leakage during vertebroplasty: an underestimated problem? Eur Spine J 14:466-473. https://doi.org/10.1007/ s00586-004-0839-5

15. Hulme PA, Krebs J, Ferguson SJ, Berlemann U (2006) Vertebroplasty and kyphoplasty: a systematic review of 69 clinical studies. Spine 31:1983-2001. https://doi.org/10.1097/01.brs.0000229254. $89952.6 b$

16. Clark W, Bird P, Gonski P, Diamond TH, Smerdely P, McNeil HP, Schlaphoff G, Bryant C, Barnes E, Gebski V (2016) Safety and efficacy of vertebroplasty for acute painful osteoporotic fractures (VAPOUR): a multicentre, randomised, double-blind, placebocontrolled trial. Lancet (London, England) 388:1408-1416. https://doi.org/10.1016/s0140-6736(16)31341-1

17. Rho YJ, Choe WJ, Chun YI (2012) Risk factors predicting the new symptomatic vertebral compression fractures after percutaneous vertebroplasty or kyphoplasty. Eur Spine J 21:905-911. https:// doi.org/10.1007/s00586-011-2099-5

18. Lin EP, Ekholm S, Hiwatashi A, Westesson PL (2004) Vertebroplasty: cement leakage into the disc increases the risk of new fracture of adjacent vertebral body. AJNR Am J Neuroradiol $25: 175-180$

19. Ahn Y, Lee JH, Lee HY, Lee SH, Keem SH (2008) Predictive factors for subsequent vertebral fracture after percutaneous vertebroplasty. J Neurosurg Spine 9:129-136. https://doi.org/10.3171/ spi/2008/9/8/129 
20. Chen WJ, Kao YH, Yang SC, Yu SW, Tu YK, Chung KC (2010) Impact of cement leakage into disks on the development of adjacent vertebral compression fractures. J Spinal Disord Tech 23:3539. https://doi.org/10.1097/BSD.0b013e3181981843

21. Nieuwenhuijse MJ, Putter H, van Erkel AR, Dijkstra PD (2013) New vertebral fractures after percutaneous vertebroplasty for painful osteoporotic vertebral compression fractures: a clustered analysis and the relevance of intradiskal cement leakage. Radiology 266:862-870. https://doi.org/10.1148/radiol.12120751

22. Lee DG, Park CK, Park CJ, Lee DC, Hwang JH (2015) Analysis of Risk Factors Causing New Symptomatic Vertebral Compression Fractures After Percutaneous Vertebroplasty for Painful Osteoporotic Vertebral Compression Fractures: A 4-year Follow-up. J Spinal Disord Tech 28:E578-583. https://doi.org/10.1097/bsd. 0000000000000043

23. Wang H, Chen X, Zhao J, Kang M, Dong R, Wang K, Qu Y (2020) Predictive Nomogram for Midterm to Long-Term Prognosis in Patients with Papillary Renal Cell Carcinoma Based on Data from the Surveillance, Epidemiology, and End Results (SEER) Program. Med Sci Monit 26:e921859. https://doi.org/ 10.12659/msm.921859

24. Park SY (2018) Nomogram: An analogue tool to deliver digital knowledge. J Thorac Cardiovasc Surg 155:1793. https://doi.org/ 10.1016/j.jtcvs.2017.12.107

25. Pennington Z, Lubelski D, Tanenbaum J, Ahmed AK, Rosato M, Passias P, Sciubba DM (2019) Utility of Patient-reported Symptoms and Health Conditions for Predicting Surgical Candidacy and Utilization of Surgery via an Outpatient Spine Clinic Nomogram. Clinical spine surgery 32:E407-e415. https://doi. org/10.1097/bsd.0000000000000838

26. Lubelski D, Ehresman J, Feghali J, Tanenbaum J, Bydon A, Theodore N, Witham T, Sciubba DM (2020) Prediction calculator for nonroutine discharge and length of stay after spine surgery. Spine Journal 20:1154-1158. https://doi.org/10.1016/j. spinee.2020.02.022

27. Xie W, Jin D, Ma H, Ding J, Xu J, Zhang S, Liang D (2016) Cement Leakage in Percutaneous Vertebral Augmentation for Osteoporotic Vertebral Compression Fractures: Analysis of Risk Factors. Clin Spine Surg 29:E171-176. https://doi.org/10.1097/ bsd.0000000000000229

28. Harrington KD (2001) Major neurological complications following percutaneous vertebroplasty with polymethylmethacrylate : a case report. J Bone Joint Surg Am 83:1070-1073. https://doi.org/10.2106/00004623-200107000-00014

29. Ren HL, Jiang JM, Chen JT, Wang JX (2015) Risk factors of new symptomatic vertebral compression fractures in osteoporotic patients undergone percutaneous vertebroplasty. Eur Spine J 24:750-758. https://doi.org/10.1007/s00586-015-3786-4

30. Fu Z, Hu X, Wu Y, Zhou Z (2016) Is There a Dose-Response Relationship of Cement Volume With Cement Leakage and Pain Relief After Vertebroplasty? Dose Response 14:1559325816682867. https://doi.org/10.1177/1559325816 682867

31. Zhan Y, Jiang J, Liao H, Tan H, Yang K (2017) Risk Factors for Cement Leakage After Vertebroplasty or Kyphoplasty: A MetaAnalysis of Published Evidence. World Neurosurg 101:633-642. https://doi.org/10.1016/j.wneu.2017.01.124

32. Zhu SY, Zhong ZM, Wu Q, Chen JT (2016) Risk factors for bone cement leakage in percutaneous vertebroplasty: a retrospective study of four hundred and eighty five patients. Int Orthop 40:1205-1210. https://doi.org/10.1007/s00264-015-3102-2

33. Ha KY, Lee JS, Kim KW, Chon JS (2006) Percutaneous vertebroplasty for vertebral compression fractures with and without intravertebral clefts. J Bone Joint Surg Br 88:629-633. https:// doi.org/10.1302/0301-620x.88b5.17345
34. Liu Q, Cao J, Kong JJ (2019) Clinical effect of balloon kyphoplasty in elderly patients with multiple osteoporotic vertebral fracture. Niger J Clin Pract 22:289-292. https://doi.org/10.4103/njcp. njcp_8_18

35. Wang Y, Zhong H, Zhou Z, Liu J, Zou MX (2017) Letter to the Editor Regarding "Analysis of Risk Factors for Secondary New Vertebral Compression Fracture Following Percutaneous Vertebroplasty in Patients with Osteoporosis." World Neurosurg 103:924-925. https://doi.org/10.1016/j.wneu.2017.02.035

36. Jesse MK, Petersen B, Glueck D, Kriedler S (2015) Effect of the Location of Endplate Cement Extravasation on Adjacent Level Fracture in Osteoporotic Patients Undergoing Vertebroplasty and Kyphoplasty. Pain Physician 18:E805

37. Gao C, Zong M, Wang WT, Xu L, Cao D, Zou YF (2018) Analysis of risk factors causing short-term cement leakages and long-term complications after percutaneous kyphoplasty for osteoporotic vertebral compression fractures. Acta radiologica 59:577-585. https://doi.org/10.1177/0284185117725368

38. Lou S, Shi X, Zhang X, Lyu H, Li Z, Wang Y (2019) Percutaneous vertebroplasty versus non-operative treatment for osteoporotic vertebral compression fractures: a meta-analysis of randomized controlled trials. Osteoporos Int 30:2369-2380. https://doi.org/ 10.1007/s00198-019-05101-8

39. Aparisi F (2016) Vertebroplasty and Kyphoplasty in Vertebral Osteoporotic Fractures. Semin Musculoskelet Radiol 20:382-391. https://doi.org/10.1055/s-0036-1592431

40. Firanescu CE, de Vries J, Lodder P, Schoemaker MC, Smeets AJ, Donga E, Juttmann JR, Klazen CAH, Elgersma OEH, Jansen FH, van der Horst I, Blonk M, Venmans A, Lohle PNM (2019) Percutaneous Vertebroplasty is no Risk Factor for New Vertebral Fractures and Protects Against Further Height Loss (VERTOS IV). Cardiovasc Intervent Radiol 42:991-1000. https://doi.org/ 10.1007/s00270-019-02205-w

41. Xie L, Zhao ZG, Zhang SJ, Hu YB (2017) Percutaneous vertebroplasty versus conservative treatment for osteoporotic vertebral compression fractures: An updated meta-analysis of prospective randomized controlled trials. Int J Surg 47:25-32. https://doi.org/ 10.1016/j.ijsu.2017.09.021

42. Cui L, Chen L, Xia W, Jiang Y, Cui L, Huang W, Wang W, Wang X, Pei Y, Zheng X, Wang Q, Ning Z, Li M, Wang O, Xing X, Lin Q, Yu W, Weng X, Xu L, Cummings SR (2017) Vertebral fracture in postmenopausal Chinese women: a population-based study. Osteoporos Int 28:2583-2590. https://doi.org/10.1007/ s00198-017-4085-1

43. Audran M, Jakob FJ, Palacios S, Brandi ML, Bröll H, Hamdy NA, McCloskey EV (2013) A large prospective European cohort study of patients treated with strontium ranelate and followed up over 3 years. Rheumatol Int 33:2231-2239. https://doi.org/10.1007/ s00296-012-2594-y

44. Kung AW, Lee KK, Ho AY, Tang G, Luk KD (2007) Ten-year risk of osteoporotic fractures in postmenopausal Chinese women according to clinical risk factors and BMD T-scores: a prospective study. J Bone Miner Res 22:1080-1087. https://doi.org/10.1359/ jbmr.070320

45. Filippiadis DK, Marcia S, Masala S, Deschamps F, Kelekis A (2017) Percutaneous Vertebroplasty and Kyphoplasty: Current Status, New Developments and Old Controversies. Cardiovasc Intervent Radiol 40:1815-1823. https://doi.org/10.1007/ s00270-017-1779-x

46. Delmas PD, Genant HK, Crans GG, Stock JL, Wong M, Siris E, Adachi JD (2003) Severity of prevalent vertebral fractures and the risk of subsequent vertebral and nonvertebral fractures: results from the MORE trial. Bone 33:522-532. https://doi.org/10.1016/ s8756-3282(03)00241-2

47. Komemushi A, Tanigawa N, Kariya S, Kojima H, Shomura Y, Komemushi S, Sawada S (2006) Percutaneous vertebroplasty for 
osteoporotic compression fracture: multivariate study of predictors of new vertebral body fracture. Cardiovasc Intervent Radiol 29:580-585. https://doi.org/10.1007/s00270-005-0138-5

48. Mudano AS, Bian J, Cope JU, Curtis JR, Gross TP, Allison JJ, Kim Y, Briggs D, Melton ME, Xi J, Saag KG (2009) Vertebroplasty and kyphoplasty are associated with an increased risk of secondary vertebral compression fractures: a population-based cohort study. Osteoporos Int 20(5):819-826. https://doi.org/10. 1007/s00198-008-0745-5

49. Marcia S, Muto M, Hirsch JA, Chandra RV, Carter N, Crivelli P, Piras E, Saba L (2018) What is the role of vertebral augmentation for osteoporotic fractures? A review of the recent literature. Neuroradiology 60:777-783. https://doi.org/10.1007/ s00234-018-2042-0

50. Lange A, Kasperk C, Alvares L, Sauermann S, Braun S (2014) Survival and cost comparison of kyphoplasty and percutaneous vertebroplasty using German claims data. Spine 39:318-326. https://doi.org/10.1097/BRS.0000000000000135

51. Hoshino N, Hida K, Sakai Y, Osada S, Idani H, Sato T, Takii Y, Bando H, Shiomi A, Saito N (2018) Nomogram for predicting anastomotic leakage after low anterior resection for rectal cancer. Int J Colorectal Dis 33:411-418. https://doi.org/10.1007/ s00384-018-2970-5

52. Iasonos A, Schrag D, Raj GV, Panageas KS (2008) How to build and interpret a nomogram for cancer prognosis. J Clin Oncol 26:1364-1370. https://doi.org/10.1200/jco.2007.12.9791

Publisher's Note Springer Nature remains neutral with regard to jurisdictional claims in published maps and institutional affiliations.

\section{Authors and Affiliations}

\section{Wenle $\mathrm{Li}^{1,2} \cdot$ Haosheng Wang ${ }^{3} \cdot$ Shengtao Dong ${ }^{4} \cdot \mathrm{Zhi}^{-R i}$ Tang $^{5} \cdot$ Longhao Chen $^{6} \cdot$ Xintian Cai $^{7} \cdot \mathrm{Zhaohui} \mathrm{Hu}^{8} \cdot$ Chengliang Yin $9,10,11$}

Wenle Li

drlee0910@163.com

Haosheng Wang

981800749@qq.com

Shengtao Dong

962921098@qq.com

Zhi-Ri Tang

gerintang@163.com

Longhao Chen

keguyixin@163.com

Xintian Cai

278996834@qq.com

1 Department of Orthopedics, Xianyang Central Hospital, Xianyang 712000, China

2 Clinical Medical Research Center, Xianyang Central Hospital, Xianyang 712000, China

3 Orthopaedic Medical Center, The Second Hospital of Jilin University, Changchun 130000, China
4 Department of Spine Surgery, Second Affiliated Hospital of Dalian Medical University, Dalian 116000, China

5 School of Physics and Technology, Wuhan University, Wuhan 430072, China

6 Graduate School, Guangxi University of Chinese Medicine, Nanning 530000, China

7 Hypertension Center of People's Hospital of Xinjiang Uygur Autonomous Region, Urumqi 830001, China

8 Department of Spinal Surgery, Liuzhou People's Hospital, Liuzhou 545000, China

$9 \quad$ National Engineering Laboratory for Medical Big Data Application Technology, Chinese PLA General Hospital, Beijing 1000853, China

10 Medical Big Data Research Center, Medical Innovation Research Division of Chinese, PLA General Hospital, Beijing 1000853, China

11 Faculty of Medicine, Macau University of Science and Technology, Macau 999078, China 